\title{
Ethical sensitivity in teaching and teacher education
}

\section{Tirri, Kirsi}

Springer Science+Business Media

2019-05-31

Tirri , K 2019 , Ethical sensitivity in teaching and teacher education . in M A Peters (ed.),

Encyclopedia of Teacher Education . Springer Nature , Springer Science+Business Media . https://doi.org/10.1007/9

http://hdl.handle.net/10138/330367

https://doi.org/10.1007/978-981-13-1179-6_183-1

unspecified

acceptedVersion

Downloaded from Helda, University of Helsinki institutional repository.

This is an electronic reprint of the original article.

This reprint may differ from the original in pagination and typographic detail.

Please cite the original version. 


\title{
Ethical Sensitivity in Teaching and Teacher Education
}

\author{
Professor Kirsi Tirri \\ Helsinki Collegium for Advanced Studies \\ University of Helsinki \\ kirsi.tirri@helsinki.fi
}

\section{Introduction}

The purpose of this chapter is to clarify the concept of ethical sensitivity in teaching and show its importance in teachers' professional ethics and teacher education. The professional status of teachers differs from country to country. In Finland, for example, teachers are considered ethical professionals who can be trusted and who share similar basic values about their work. These values are established in the ethical codes for teachers, which were first published in Finland in 1998. The values are dignity, truthfulness, fairness, responsibility, and freedom. In 2017 the Teachers' Union in Finland continued to strengthen the professional status of its members and established the Comenius' Oath for teachers. The purpose of this oath was to support teachers and provide a concrete reminder of the ethical foundation of their profession. The freedom given teachers challenges them constantly to develop their ethical skills with regard to their students, colleagues, themselves, and the networks with which they cooperate. Ethical sensitivity provides the eyes for teachers to see the needs, dilemmas, and possibilities in their daily work.

Ethical sensitivity in teacher-student relationships means that the best interests of a student guide the teacher to understand the different needs of all kinds of learners. The younger the student, the more the teacher needs cooperation with other adults. Today, teachers in Finland team-teach and collaborate with parents and other experts to meet their students' diverse educational needs. Teachers also consult school psychologists and other experts in the search for what is the best for their students. And teachers need ethical sensitivity with respect to their own work. They should constantly reflect on their own skills with self-evaluation and strive to improve and develop as professionals. In Finland, the philosophy of life-long learning means that teachers have both the right and the responsibility to pursue personal development and self care. They are expected to grant the same right to their colleagues as members of the teaching profession. With regard to their schools, teachers should reflect on the balance between individual rights and the needs of their learning community. Because teachers are active agents in their respective societies, they should also consider the impact of their work on the future of their society.

Bebeau, Rest, and Narvaez (1999) have defined ethical sensitivity as the awareness of how our actions affect other people. Ethical sensitivity makes it possible for teachers to identify the moral issues involved in teaching. To respond to a situation in a moral way, a teacher must be able to perceive and interpret events in a manner that leads to ethical action. An ethically sensitive teacher observes various situational cues and can visualize several alternative actions in response to that situation. The teacher draws on many aspects, skills, techniques, and components of 
interpersonal sensitivity. These include taking the perspective of others (role taking), cultivating empathy for others, and interpreting a situation based on imagining what might happen and who might be affected. Ethical sensitivity is closely related to interpersonal intelligence, including emotional and social intelligences, which can be defined as the abilities to understand and get along well with others. These abilities make cooperation possible, which is needed in the teaching, studying, and learning processes of education.

Ethical sensitivity helps teachers to identify moral issues and dilemmas. Teachers have identified the following moral dilemmas in connection with their profession: 1) personal matters related to teachers' work (e.g., deciding how to deal with students or colleagues); 2) the morality of students' behavior with regard to school and work (e.g., harassment); 3) the rights of minority groups (e.g., cultural conflicts and religious issues); and 4) common rules at school (e.g., no smoking or playing cards) (Tirri, 1999). Dilemmas such as these invite teachers to consider the values of dignity, truthfulness, fairness, responsibility, and freedom in their search for the best possible solutions for their students. The nature of moral dilemmas makes it impossible to find a solution that would please everyone involved. Following the ethical guideline of the best interest of a student, for example, might lead to a solution that does not work in the best interest of a colleague. Sometimes a teacher needs to take the side of one student and discipline another student. These conflicting interests call for ethical sensitivity and require teachers to find the educationally best-justified solutions.

In the following sections, ethical sensitivity is defined and operationalized as a set of ethical skills that can be learned and developed in teacher education. Ethical sensitivity can also be measured with a valid instrument that makes it possible to compare teachers from different cultural backgrounds. Empirical findings concerning teachers' ethical sensitivity as measured with the Ethical Sensitivity Scale Questionnaire (ESSQ) are presented below, and the cultural aspects are discussed along with implications for teacher education.

\section{What is Ethical Sensitivity in Teaching?}

We know from earlier empirical research that moral experts demonstrate holistic orientations and skill sets within four processes of ethical behavior, namely, ethical sensitivity, ethical judgment, ethical motivation, and ethical action (Bebeau, Rest, \& Narvaez, 1999). Although these skills are essential, the most important is ethical sensitivity, because it is needed for recognizing and understanding ethical problems and their cues. Thus, ethical sensitivity is possibly a key aspect of teachers' moral competence in pedagogical encounters. First, teachers need the skills to identify moral issues and dilemmas in their work. Empirical studies in secondary-school contexts indicate that teachers mostly identify moral dilemmas related to their students and colleagues (Tirri, 1999). In the context of early education, Finnish teachers identified moral conflicts with parents as the primary dilemma in "finding [a solution in] the best interest of a child" (Tirri \& Husu, 2002). Some studies on ethical sensitivity involving urban Finnish teachers have investigated critical incidents in their work. Teachers identified critical incidents having emotional and moral content as those related to the school principal, students and family members, teachers, and the school community. Teachers reported commitment, caring, cooperation, and respect as the most successful emotional expressions in these situations. These 
expressions reflected ethical sensitivity skills, especially in reading and conveying emotions (Hanhimäki \& Tirri, 2009).

Narvaez and Endicott (2009) have operationalized ethical sensitivity in terms of seven skills: (1) reading and expressing emotions, (2) taking the perspective of others, (3) caring by connecting to others, (4) working with interpersonal and group differences, (5) preventing social bias, (6) generating interpretations and options, and (7) identifying the consequences of action and options. These skills have guided the development of the Ethical Sensitivity Scale Questionnaire (ESSQ), which can be used to assess teachers' or students' ethical sensitivity skills (Tirri \& Nokelainen, 2011). The questionnaire can be used for both self-evaluation and for the assessment of teachers and students as part of their professional development plan.

The original instrument consists of 28 items on a Likert scale, ranging from 1 (totally disagree) to 5 (totally agree). The ESSQ items were designed to apply to people from different backgrounds and cultures. This allows the instrument to be used in a multicultural society and in cross-cultural studies. The instrument's statements described the issues and values that the respondent considered important to him or her. Each of the seven dimensions was operationalized in the questionnaire with four statements. For example, the first category, Reading and expressing emotions, was measured with the item ess1_1: "In conflict situations, I am able to identify other persons' feelings." The original instrument has been tested with regard to psychometric properties, and the results indicate that it is a promising ethical sensitivity measurement instrument that can be applied to various learning contexts, both in traditional faceto-face situations and in online learning environments (Tirri \& Nokelainen, 2011). The instrument has been tested with both student and teacher populations in diverse settings. Regarding the development of the ESSQ, a four-factor model with 16 items captured the essential aspects of the ethical sensitivity of teachers in the contexts of Finland and Iran. The study also revealed that both the Iranian and the Finnish teachers reported high levels of ethical sensitivity. This finding is in line with existing literature, which holds that teaching is a moral activity by nature and caring is an essential aspect of teachers' professional ethics.

\section{Cultural Aspects of Ethical Sensitivity}

The ethical sensitivity questionnaire (ESSQ) has been tested with both secondary-school students and students in higher education from different cultural settings. The results showed that Finnish students who had received religious education in school and church contexts rated their ethical sensitivity higher than did their younger peers without religious education (Tirri \& Nokelainen, 2011). This finding supports the idea that ethical sensitivity can be developed and taught. In both Finnish and Dutch studies, female students estimated their ethical skills higher than their male peers. This tendency can be explained by the types of items measuring ethical sensitivity skills. Most of them measure "caring ethics" with emotional and social intelligence, which can be considered feminine in nature. The results from Finnish secondary-school students and Dutch higher-education students indicate that more academically gifted students estimated their ethical skills higher than their average ability peers. This finding supports the notion advanced by other 
researchers, namely, that gifted students have a privileged position in the maturation of moral thinking because of their precocious intellectual growth.

Generally, teachers evaluate their ethical sensitivity quite high with an emphasis on caring ethics. In a comparative study of Finnish $(\mathrm{N}=864)$ and Iranian $(\mathrm{N}=556)$ teachers' ethical sensitivity, we found that the dimension "caring by connecting to students" is a central and culture-invariant element of teachers' ethical sensitivity. In other words, connecting shows that establishing good and caring relationships with students is a central issue for teacher educators in both countries. We also found culture-dependent elements in teachers' ethical sensitivity. "Taking the perspective of others" was more difficult for Iranian teachers than for Finnish teachers. This finding can be explained by the collectivism and power distance of Iranian culture. In Iran, accepting Islamic values and meanings is a priority in social interactions. Thus, in many social conflicts, "individual agency" and people with secular values are ignored, while the "collective structure" and individuals with a religious orientation are acknowledged. In Western societies such as Finland, democratic values are a core philosophy in which respecting the perspective of others is highly emphasized in social interactions (Gholami, Kuusisto, \& Tirri, 2015).

The results of comparative studies show that ethical sensitivity should be considered as an important moral competency for teachers and thus should be part of their professional development and education. Caring by connecting with students is a central element of teachers' ethical sensitivity, and connecting shows that establishing good and caring relationships with students is a central issue for teacher educators in both countries. Moreover, this dimension is a culturally invariant aspect of ethical sensitivity in a teaching context, one that should be highlighted by teacher educators in training programs all over the world. Teacher educators should consider cultural aspects of ethical sensitivity in the context of teaching. Based on the empirical findings, ethical sensitivity is represented in different ways in teachers from different countries.

Cultural aspects can also be seen in teachers' attitudes to different cultures and religions in their own countries. For example, Finland's most visible religious minority is Muslim; thus, teaching about this religion could be justified among Finnish teachers. However, current research results show that teachers in Finland have more positive attitudes to teaching about differences in general than in teaching about Islam. These results reflect the general negativity toward Islam evident in other countries as well and indicate that Finnish teachers are more willing to deal with forms of difference other than religious minorities. This trend calls for teacher education in ethical sensitivity to religions other than the teachers' own. Teachers could profit from contacts and communication with members of other religions, especially Muslims, to develop their ethical sensitivity. In our studies of Finnish teachers, previous involvement with other cultures is an indicator of student teachers' beliefs that Muslim students will integrate into Finnish society. The experiences of other cultures are shown to be a global indicator of more positive attitudes and even, in many studies, of sensitivity to differences.

\section{Ethical Sensitivity and Teacher Education}

Ethical sensitivity in teaching and teacher education is still a very new area of research. More often, ethical judgment is emphasized and implemented in teacher education programs. In this 
chapter, ethical sensitivity has been introduced as an important ethical skill for all teachers. Before a teacher can make just and caring ethical judgments in dealing with moral issues and dilemmas, he or she needs to see the viewpoints of all parties involved. Above all, the teacher needs to identify the moral issue or dilemma in an educational context. The twenty-first century is introducing new areas of teaching and learning, such as digital learning and inclusive education, and these areas require studies related to ethical sensitivity.

In this chapter, studies on the ethical sensitivity of teachers, mainly from Finland, have been reviewed. Both qualitative and quantitative findings have been presented along with crosscultural comparisons. The findings demonstrate that the ESSQ instrument developed to measure ethical sensitivity works very well in different cultures. All of these studies indicate that the instrument can be used to assess the ethical sensitivity of teachers and students in different cultures and can function as a helpful tool in teachers' self-evaluation and professional development.

Ethical sensitivity is closely connected to intercultural and interreligious sensitivities. There is research evidence from many countries that teachers' attitudes to some religious groups, for example, Muslim students, are not very positive. Teacher education is needed to help teachers in every subject and grade level acknowledge and develop their ethical, intercultural, and interreligious sensitivities. Teacher educators all over the world should be guided to reflect on the special characteristics of teachers' ethics in their own countries and identify the dimensions in ethical sensitivity where both pre-service and in-service teachers might require more education.

The current challenges in teacher education all over the world include the growing diversity among students and the expectations of teachers to meet the varied needs of diverse learners. High-level ethical and pedagogical skills would help teachers cope with these challenges. Moreover, the learning environments themselves are changing, and teachers need to master both face-to-face and virtual teaching settings. Teachers are preparing their students for the future and should therefore acknowledge the skills needed for the twenty-first century in their instruction. Ethical skills, including ethical sensitivity, would provide students with valuable assets in facing the challenges of tomorrow.

The values of dignity, truthfulness, fairness, responsibility, and freedom should be introduced to teachers, who should be able to explain what those values mean to them in terms of real-world teaching and learning in school settings. Teachers could be guided to identify practical examples where there is a gap, either in themselves or in their school community, between values and behavior. We should develop methods that help teachers put their values into practice. Value clarification is one possible means for starting this process.

In pre-service education, student teachers should be introduced to everyday school life, including moral dilemmas and critical incidents that require ethical sensitivity on the part of the teacher. Introduction to these dilemmas and incidents should come first through narrative learning and case studies based on real-life events. These incidents can also be used in role play, whereby preservice teachers can take turns acting in different roles, for example, as a parent or a colleague, and practice empathy and role-taking skills. Teacher education should also provide a strong knowledge base in professional ethics to help student teachers reflect on moral dilemmas and 
critical incidents in dealing with multiple ethical frameworks. In-service teachers should also be guided to update their knowledge of professional ethics with the current research in teaching. The use of concrete contemporary cases motivates teachers to take part in such education and develop their ethical skills. Researchers in moral education can provide current knowledge on the moral core of teaching for this in-service education. Combining theoretical knowledge of ethics with practical knowledge of teaching can serve our future teachers best in their life-long learning effort to become ethically sensitive professionals.

\section{References}

Bebeau, M., Rest, J., \& Narvaez, D. (1999). Beyond the promise: A perspective on research in moral education. Educational Researcher, 28(4), 18-26.

Gholami. K., Kuusisto, E. \& Tirri, K. (2015). Is ethical sensitivity in teaching culturally bound? Comparing Finnish and Iranian teachers' ethical sensitivity. Compare: A Journal of Comparative and International Education, 45(6), 886-907. DOI: 10.1080/03057925.2014.984588

Hanhimäki, E. \& Tirri,K. (2009). Education for ethically sensitive teaching in critical incidents at school. Journal of Education for Teaching, 35(2), 107-121.

Narvaez, D. \& Endicott, L. (2009). Ethical Sensitivity, Nurturing Character in the Classroom, Ethex Series Book 1, Alliance for Catholic Education Press.

Tirri, K. (1999). Teachers' perceptions of moral dilemmas at school. Journal of Moral Education 28 (1), 31-47.

Tirri, K. \& Husu, J.( 2002). Care and responsibility in "the best interest of the child": relational voices of ethical dilemmas in teaching. Teachers and Teaching, 8(1), 65-80.

Tirri, K. \& Nokelainen, P. (2011). Measuring multiple intelligences and moral sensitivities in education. Rotter-dam/Taipei: Sense Publishers. 